\title{
Scintigraphic Imaging of Paediatric Thyroid Dysfunction
}

\author{
J. Clerc ${ }^{a} \quad$ H. Monpeyssen ${ }^{a} \quad$ A. Chevalier ${ }^{a} \quad$ F. Amegassi ${ }^{a} \quad$ D. Rodrigue ${ }^{b}$ \\ F.A. Leger ${ }^{a} \quad$ B. Richard ${ }^{a}$ \\ a Department of Nuclear Medicine, Hôpital Cochin and ${ }^{b}$ Department of Paediatric Endocrinology, \\ Hôpital Saint-Vincent-de-Paul, Faculté de Médecine René Descartes Paris 5, Paris, France
}

\section{Key Words}

Thyroid scintigraphy $\cdot$ Congenital hypothyroidism .

Paediatric thyrotoxicosis $\cdot$ Thyroid ultrasound imaging

\begin{abstract}
Imaging of thyroid dysfunction is safe and clinically relevant in children. In congenital hypothyroidism (CH), thyroid imaging permits a precise characterization of the aetiology, which is important for genetic counselling and clinical management. $\mathrm{CH}$ may be due to thyroid dysgenesis (ectopia, hypoplasia and athyrosis) or occurs in eutopic glands. In the latter, hypothyroidism may be either transient, especially after iodine overload, or due to permanent autosomal recessive dyshormonogenesis. Thyroid scintigraphy (TS) with either ${ }^{99 \mathrm{~m}_{\mathrm{TCO}}}{ }_{4}$ or ${ }^{123}$ I will identify ectopic thyroid tissue, which is the commonest cause of $\mathrm{CH}$. However, recent reports favour the use of ${ }^{123}$, which enhances the accuracy of the aetiological classification. In cases of eutopic thyroid, the measurement of ${ }^{123}$ I uptake before and after perchlorate administration evaluates the organification process. At all ages, colour Doppler ultrasound scanning (CDU) is helpful in assessing thyroid volume, in identifying nodules and in characterizing tissue vascularization. TS and CDU images of most paediatric thyroid dysfunctions are presented.
\end{abstract}

Copyright ๑ 2008 S. Karger AG, Basel
(C) 2008 S. Karger AG, Base

0301-0163/08/0701-0001\$24.50/0

Fax +4161306 1234 E-Mail karger@karger.ch www.karger.com
Accessible online at:

www.karger.com/xxx
The overall incidence of congenital hypothyroidism $(\mathrm{CH})$ is about 1 in 4,000 and approximately $85 \%$ of the cases are sporadic, while $15 \%$ are hereditary. $\mathrm{CH}$ may be due to defects in thyroidal ontogeny (75\%), a group of diseases known as thyroid dysgenesis (TD), to permanent abnormal thyroid hormone synthesis (10\%) also called dyshormonogenesis (DHG), or finally to a transient inhibition of thyroid hormone synthesis, mainly caused by iodine overload in immature glands $[1,2]$. There is growing evidence that precise characterization of thyroid dysfunction is helpful in improving both medical care and understanding of the underlying disease [3]. Neonatal screening of $\mathrm{CH}$ has proved effective in preventing mental retardation and growth failure. L-Thyroxine supplementation must be started immediately since the psychometric final outcome strongly depends on the earliness of the hormonal therapy $[4,5]$. Because $\mathrm{CH}$ may be permanent or transient, especially if the thyroid is normally located and in premature births, imaging often plays an important role in avoiding unnecessarily long $\mathrm{T}_{4}$ therapy in patients with transient diseases or in optimizing thyroxine supplementation in permanent cases [6].

The pathogenesis of TD remains largely unknown while DHG occurring in normally located glands often reveals a defective mutation of the enzymatic machinery of the thyreocyte [7]. The classification of $\mathrm{CH}$ can be difficult since genetic abnormalities are not always expressed in neonates and because the prevalence of transient hy-

E-Mail jerome.clerc@cch.aphp.fr 
Fig. 1. Location of dysplastic and accessory thyroid tissue. Dysplastic and accessory thyroid tissue can be separated according to its structure, cystic (wave-filled circles) or solid (grey circles), and to its location, which is presented in a left view (left) and in a front view (right) of the neck. 1 = Lingual thyroid; 2 = suprahyoidal ectopic tissue; 3 = prehyoidal tissue: thyroglossal duct cyst and solid ectopia, some of which can be partly intrahyoidal; 4 = infrahyoidal tissue, before the thyroid and cricoid cartilages; 5 = pyramidal lobe which may present with cyst or true nodule, $7=$ infrathyroidal accessory tissue in the laryngotracheal area; $8=$ intrathoracic thyroid nests which can be seen in the mediastinum, within the oesophagus mucosa and even in the pericardium and the heart.

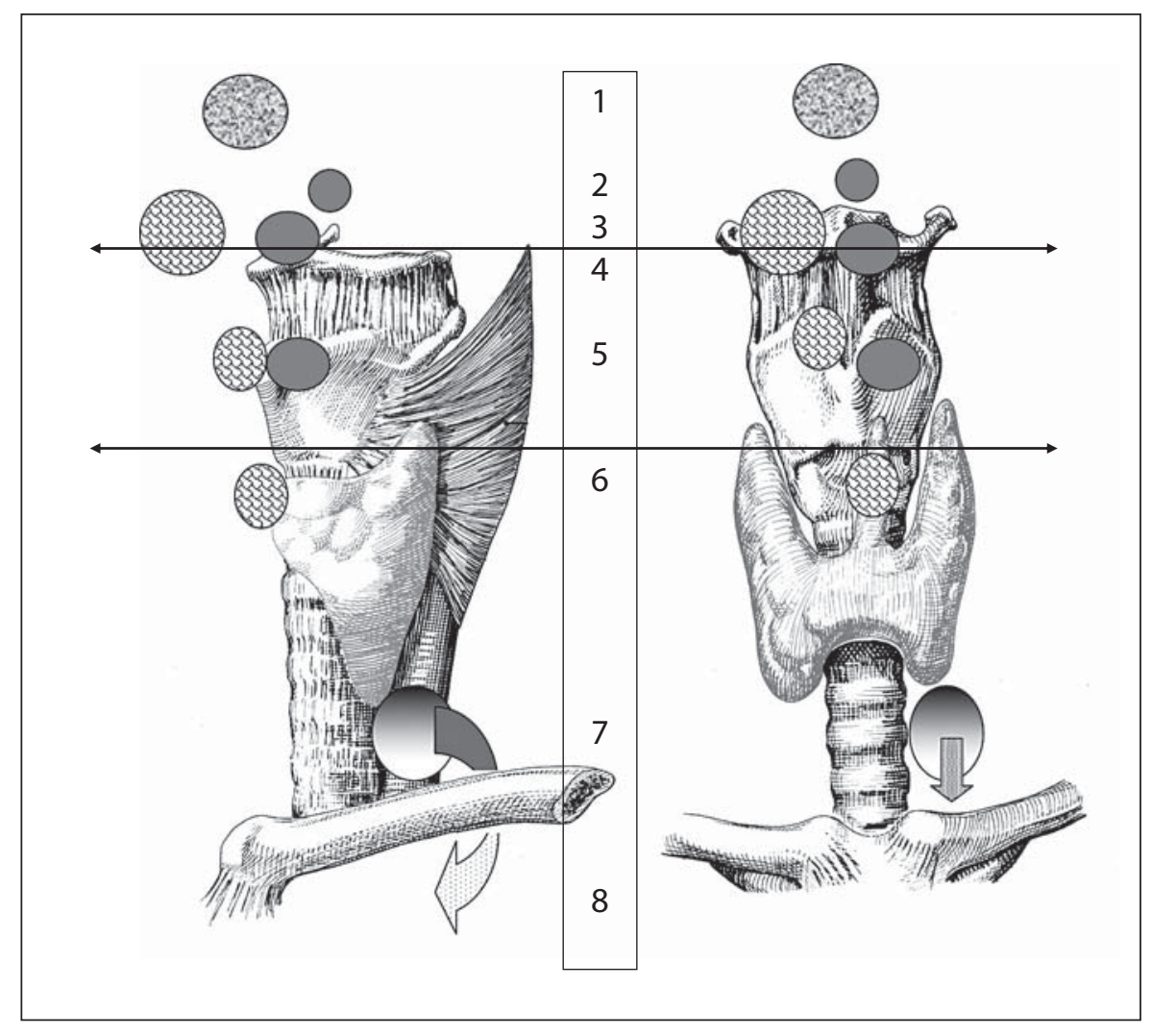

pothyroidism is poorly estimated and varies widely with environmental factors.

Thyrotoxicosis is mainly due to Graves' disease, but there may be some specific non-autoimmune aetiologies in young patients.

This article reviews medical practices and presents informative imaging contributions to the diagnosis of most paediatric thyroid dysfunctions. Source data come from Medline, endocrinology textbooks and imaging guidelines. Thyroid imaging is of little interest in central hypothyroidism and will not be discussed here.

\section{Morphofunctional Development of Thyroid and Consequences for Imaging}

The thyroid gland develops from a midline endodermal thickening in the pharyngeal floor at embryonic day (E) 20 (E20) [8]. The endodermal pit formed by these cells narrows to form the thyroglossal duct which further expands caudally driven by the aortic morphogenesis. This explains why thyroid nests can be seen from the site of initial budding of the median anlage, called the foramen caecum, to the mediastinum. The caudal end of the thyroglossal duct proliferates laterally to form a bilobated gland by E30. This apparent descent and lateral expansion of the organ may merely result from relocalization of the thyroid relative to the heart development and to horizontal stretching by the cervical structures. The thyroglossal duct will finally partly fragment and degenerate (E40) and is often visible in adults by thyroid scanning in an upper and median location in the neck or as a pyramidal lobe. In the new gland, thyroid cells will differentiate towards thyroid hormone synthesis which is detectable from gestational week 11 [9].

These phases of thyroid organogenesis explain the possible locations of ectopic or accessory thyroid tissue, depicted and readily classified by imaging (fig. 1).

\section{Thyroid Paediatric Scan and Colour Doppler Ultrasonography}

The contrast of the thyroid scan image depends on several factors including the presence and thickness of the functional tissue, the isotopic concentration and the 
signal-to-noise ratio in the imaged region. The resolution of the images should be 5-7 mm. Both ${ }^{123} \mathrm{I}$ and ${ }^{99 \mathrm{~m}} \mathrm{TcO}_{4}$ ( ${ }^{99 \mathrm{~m}} \mathrm{Tc}$ pertechnetate) can be used. Imaging can be performed as of $20 \mathrm{~min}$ after intravenous injection $\left({ }^{99 \mathrm{~m}_{\mathrm{TcO}}}\right)$ or between 30 and $120 \mathrm{~min}\left({ }^{123} \mathrm{I}\right)$, when TSH-responsive tissue is present. When using ${ }^{123} \mathrm{I}$, later acquisitions (120 min to $24 \mathrm{~h}$ ) may be useful either to study the organification process or if the contrast of the precocious image is faint [sodium/iodide symporter (NIS) defect, hypoplasia and TSH unresponsiveness]. Several uptake measurement procedures have been described using the gamma camera [10], as thyroid probes are not suitable in the case of children. When the baseline ${ }^{123} \mathrm{I}$ uptake is high in $\mathrm{CH}$, a perchlorate $\left(\mathrm{ClO}_{4}^{-}\right)$discharge test is indicated. A relative fall of below $10 \%$ is considered as normal, while a $10-50 \%$ (>50\%) fall indicates a partial (complete) organification defect, respectively. Some authors ask for a relative fall of over $90 \%$ to diagnose a complete organification defect. The newly revised medical exposure Directive 97/43/Euratom requires medical radiation exposure to be reduced as much as possible, especially in babies and children. The effective dose is usually considered to be significant with ${ }^{123} \mathrm{I}$ as compared to ${ }^{99} \mathrm{mcO}_{4}$ in adults [11], but is in reality quite similar and very low with both isotopes, because much lower activities can be injected with ${ }^{123}$ I (table 1). In addition, children presenting with athyrosis, hypoplasia and defective thyrotropin hormone receptor (R-TSH) or NIS have no or strongly impaired isotopic uptake. In iodine overload and in some DHG defects, the iodine uptake is often reduced or will further decrease after perchlorate administration. Finally, a significant thyroidal dose may be observed in ectopic thyroid, thyroglobulin ( $\mathrm{Tg}$ ) or iodotyrosine dehalogenase (DEHAL1) defects [12], in transient disorders and of course in thyrotoxicosis aetiologies where the uptake is preserved. There are no data reporting any detrimental outcome related to a previously performed scan in these patients, while the clinical relevance of rapidly establishing an accurate diagnosis is widely accepted. Finally the average thyroid dose, when it exists, is likely to be lower than $4.5 \mathrm{mSv} / \mathrm{MBq}$ in infants [13], while the cellular dose to the thyreocyte remains unknown.

High-resolution ultrasound probes $(8-13 \mathrm{MHz})$ must be used since the structures studied may be very thin. In addition, colour Doppler is advisable because the ectopic/ hyperplastic tissue is hypervascular. Colour Doppler ultrasound (CDU) can accurately measure the thyroid volume which varies in children according to age, body mass index and iodine intake in their country, as widely reported. CDU can also identify cysts of the thyroglossal
Table 1. Paediatric thyroid scintigraphy - isotopes

\begin{tabular}{lll}
\hline & ${ }^{123} \mathrm{I}$ & ${ }^{99 \mathrm{~m} \mathrm{Tc}}$ \\
\hline $\begin{array}{ll}\text { Activity, } \mathrm{MBq} \\
\quad \text { Baby }\end{array}$ & $1.2-2$ & $10-20$ \\
$\quad$ Children & $10 \times \mathrm{AWF}$ & $74 \times \mathrm{AWF}$ \\
Thyroidal peak activity at & $3-24 \mathrm{~h}$ & $20 \mathrm{~min}$ \\
Imaging at & $0.5-24 \mathrm{~h}$ & $20-35 \mathrm{~min}$ \\
Thyroidal concentration, \%/g & $0.6-0.8(2 \mathrm{~h})$ & $0.07-0.28$ (30 min) \\
Perchlorate $\left(\mathrm{ClO}_{4}^{-}\right)$dose, $\mathrm{mg}$ & & \\
$\quad$ Baby & 40 & - \\
$\quad$ Children & $40($ body & - \\
& surface/0.2) & \\
Effective dose, $\mathrm{mSv} / \mathrm{scan}$ & $0.65-1$ & $0.4-0.8$ \\
Thyroid dose, $\mathrm{mSv} / \mathrm{MBq}$ & 9.8 & 0.9 \\
Thyroid dose, $\mathrm{mSv} / \mathrm{scan}$ & & \\
$\quad$ Baby & 15 & 13 \\
$\quad$ Child $(40 \mathrm{~kg})$ & 74 & 50 \\
\hline
\end{tabular}

AWF (adult weighting factor): 0.27 (10 kg), 0.46 (20 kg), 0.63 (30 kg), 0.76 (40 kg), 0.88 (60 kg).

duct or within the thyroid itself and can provide additional visualization of neck structures such as thymic tissue or other neck masses [14], be they solid (lymph nodes, tumours, fibromatosis colli) or cystic (lymphangiomas, branchial cleft cysts).

\section{Paediatric Imaging of Hypothyroidism}

The main features of thyroid imaging in hypothyroidism are reported in table 2. We will first focus on $\mathrm{CH}$ and then consider transient and acquired disorders.

\section{The Paediatric Thyroid Scan and CH in the Literature}

Most published imaging studies distinguish on the one hand dysplastic glands, mainly athyrosis or ectopic thyroid, and on the other eutopic, normal or dyshormonogenetic glands [6, 15-17]. According to the presented review of the literature (table 3 ), dysplastic glands account for $74.4 \%$ of the cases with about $43 \%$ of these being ectopic (range: $11-63$ ) and 31\% athyrotic (range: 18-61). Eutopic thyroid is reported in $\mathrm{CH}$ by thyroid scan in $26 \%$ of cases (range: 12-57). These discrepancies between studies include variations in disease classification, recruitment bias for imaging since many children with $\mathrm{CH}$ never had thyroid imaging, demographic factors and iso- 
Table 2. Thyroid imaging according to paediatric aetiology of hypothyroidism

\begin{tabular}{|c|c|c|c|c|c|}
\hline \multirow[t]{2}{*}{ Aetiology } & \multicolumn{3}{|l|}{ Thyroid scan } & \multirow[t]{2}{*}{ Ultrasound } & \multirow[t]{2}{*}{ Other features } \\
\hline & contrast & Up. & PDS & & \\
\hline \multicolumn{6}{|l|}{ Dysgenesis $(1: 4,500)$} \\
\hline Ectopia & focal & $\mathrm{N}, \downarrow$ & $+/-$ & focal, hyperE & relatively frequent \\
\hline Athyreosis & $\mathrm{Ab}$ & $\mathrm{Ab}$ & uw & absent tissue & possible FN with US \\
\hline Hypoplasia & faint, diffuse & $\mathrm{N}, \downarrow$ & uw & reduced volume & possible FP with US \\
\hline Hemiagenesis & single lobe & $\mathrm{N}$ & uw & single lobe & absent left lobe $80 \%$ \\
\hline Thyroglossal duct cysts & $\mathrm{Ab}$ & $\mathrm{Ab}$ & uw & cystic & prefer US \\
\hline Pyramidal lobe, thyroid rests & focal & $\mathrm{N}$ & uw & focal & possible FN with US \\
\hline \multicolumn{6}{|l|}{ Dyshormonogenesis $(1: 30,000)$} \\
\hline Defective R-TSH & faint or $\mathrm{Ab}$ & $\mathrm{N}, \downarrow$ & uw & volume $\downarrow$ & hypoplasia, ${ }^{123} \mathrm{I}>{ }^{99 \mathrm{~m}} \mathrm{Tc}$ \\
\hline NIS defects & faint or $\mathrm{Ab}$ & $\mathrm{Ab}, \downarrow$ & uw & goitre & no ${ }^{123}$ I stomach uptake \\
\hline TPO mutations & diffuse goitre & $\mathbf{t}$ & $\mathrm{C}>\mathrm{P}$ & goitre & relatively frequent \\
\hline THOX mutations & diffuse goitre & $\mathbf{t}$ & $\mathrm{P} / \mathrm{C}$ & goitre & rare \\
\hline Pendrin mutation & diffuse goitre & $\mathbf{t}$ & $\mathrm{P} / \mathrm{C}$ & goitre & deafness (cochlear MRI) \\
\hline Abnormal Tg & diffuse goitre & $\mathbf{\uparrow}$ & no wo & goitre & \\
\hline Other Tg defects ${ }^{\mathrm{a}}$ & diffuse goitre & $\mathbf{t}$ & no wo & goitre & rare, late onset \\
\hline Iodotyrosine DEHAL defect & diffuse goitre & $\mathbf{t}$ & no wo & goitre & late onset \\
\hline \multicolumn{6}{|l|}{ Miscellaneous } \\
\hline Subtotal surgery & Var. & Var. & uw & Var. & cervical scar \\
\hline $\mathrm{TSH}-\mathrm{R}-\mathrm{Ab}$ & faint or $\mathrm{Ab}$ & $\mathrm{Ab}, \downarrow$ & uw & normal & maternal autoimmunity \\
\hline Iodide overload & diffuse goitre & $\mathbf{t}$ & $\mathrm{P} / \mathrm{C}$ & goitre & baby $<36$ weeks \\
\hline Severe iodide deficiency & diffuse goitre & $\uparrow$ & - & goitre & endemic goitre area \\
\hline Thyroiditis ${ }^{\mathrm{b}}$ & Var. & Var. & uw & Var. & US often hypoE \\
\hline Down's syndrome & normal & Var. & $\mathrm{P}$ & normal & consider autoimmunity \\
\hline Pseudohypoparathyroidism & normal & Var. & uw & normal & \\
\hline
\end{tabular}

$\mathrm{Up}=\mathrm{Uptake}$; PD = perchlorate discharge test: the wash out (wo) of ${ }^{123} \mathrm{I}$ may be partial (P, wo: $\left.10-50 \%\right)$ or complete (C, wo $>50 \%$ ); $\mathrm{N}=$ normal; hyperE = hyperechoic ultrasound pattern; $\mathrm{Ab}=$ absent; $\mathrm{uw}=$ unwanted test; $\mathrm{FN}=$ false-negative result; $\mathrm{US}=\mathrm{ultrasound}$; $\mathrm{FP}$ = false-positive result; Var. = variable; hypoE = hypoechoic ultrasound pattern; DEHAL = iodothyrosine dehalogenase.

a Abnormality in $\mathrm{Tg}$ pinocytosis or hydrolization.

${ }^{\mathrm{b}}$ Imaging varies widely in thyroiditis according to the aetiology (see also table 4) and the evolution of the disease which is often bi- or triphasic (hyper $\Rightarrow \mathrm{eu}$, or hyper $\Rightarrow \mathrm{eu} \Rightarrow$ hypo, etc.).

topic selection. Most authors consider hypoplastic glands as dysplastic though they are correctly located in the neck. Hypoplastic glands in permanent $\mathrm{CH}$ account for about $15 \%$ of normally located glands. Some ectopic glands also present with organification defects but are usually classified in the dysplastic group [16]. The eutopic group includes patients with transient hypothyroidism $(>30 \%)$ in an apparently normal gland or permanent hypothyroidism, with or without goitre. Most of the latter patients have dyshormonogenetic goitres of which 30 $50 \%$ have a positive perchlorate discharge test.

Based on the present review and on studies which specifically compared isotopes, ${ }^{123} \mathrm{I}$ appears slightly more advisable than ${ }^{99 \mathrm{~m}} \mathrm{Tc}$ in $\mathrm{CH}$ [17-19]. Indeed, the overall proportion of patients with eutopic or dysplastic glands significantly differs depending on the pharmaceutical product used. With ${ }^{99 \mathrm{~m}} \mathrm{Tc}$, more patients are wrongly overclassified as athyrotic due to the lack of sensitivity of the ${ }^{99 \mathrm{~m}} \mathrm{Tc}$ thyroid scintigraphy (TS). Ectopic glands can be identified by both isotopes, but in cases where the ectopic tissue is close to the mouth, it can be masked or obscured by oral activity, using ${ }^{99} \mathrm{~m}^{\mathrm{TcO}_{4}}$. Finally, eutopic tissue and dyshormonogenetic goitres are best identified with ${ }^{123} \mathrm{I}$ which further indicates where the molecular defect takes place. However, in centres where ${ }^{123} \mathrm{I}$ is not routinely available, ${ }^{99} \mathrm{TCO}_{4}$ can nevertheless effectively identify most patients with thyroid aplasia and eutopic goitres and identify a large proportion of patients with ectopy. 
Table 3. Diagnosis of congenital hypothyroidism according to the isotope and aetiolgy

\begin{tabular}{|c|c|c|c|c|c|}
\hline \multirow[t]{2}{*}{ Authors } & \multirow[t]{2}{*}{$\mathrm{n}$} & \multirow{2}{*}{$\begin{array}{l}\text { Isotope } \\
{ }^{99 \mathrm{~m}} \mathrm{Tc} /{ }^{123} \mathrm{I}\end{array}$} & \multirow{2}{*}{$\begin{array}{l}\text { Eutopic thyroid } \\
\text { normal or DHG, \% }\end{array}$} & \multicolumn{2}{|c|}{ Dysplastic thyroid, \% } \\
\hline & & & & ectopia & athyrosis \\
\hline Connelly et al. [1] & 199 & $199 / 0$ & 11.7 & 46 & 33 \\
\hline \multirow[t]{3}{*}{ Panoutsopoulos et al. [17] } & 584 & $96^{\mathrm{a}} / 0$ & 12.5 & 26 & 61.5 \\
\hline & & $73 / 0$ & 19.2 & 52 & 28.8 \\
\hline & & $0 / 220$ & 13.6 & 63.2 & 23.2 \\
\hline Lobo et al. [55] & 189 & $189 / 0$ & 29.1 & 47.1 & 29.1 \\
\hline Sfakianakis et al. [6] & 103 & $103 / 0$ & 35 & 29.9 & 33.9 \\
\hline Pusuwan et al. [15] & 27 & $27 / 0$ & 40.8 & 11.1 & 38.1 \\
\hline el-Desouki et al. [16] & 147 & $147 / 0$ & 36 & 42.2 & 21.8 \\
\hline Kreisner et al. [26] & 88 & $88 / 0$ & 20.4 & 27.3 & 52.3 \\
\hline Meller et al. [31] & 38 & $0 / 38$ & 57.8 & 23.7 & 18.4 \\
\hline De Bruyn et al. [25] & 54 & $54 / 0$ & 18.5 & 48.1 & 33.3 \\
\hline \multirow[t]{2}{*}{ Schoen et al. [19] } & 210 & $67 / 0$ & 31 & 32 & 34 \\
\hline & & $0 / 143$ & 48 & 22 & 29 \\
\hline \multirow[t]{2}{*}{ Verelst et al. [23] } & 69 & $69 / 0$ & 10.1 & 62.4 & 27.5 \\
\hline & & & Eutopic & Ectopic & Athyrosis \\
\hline Total & & & $380(25.5 \%)$ & $644(43.2 \%)$ & $465(31.2 \%)$ \\
\hline${ }^{123} \mathrm{I}$ & & $26.8 \%$ & $121(30.2 \%)$ & $180(44.9 \%)$ & $100(24.9 \%)$ \\
\hline${ }^{99 \mathrm{~m}} \mathrm{Tc}(\mathrm{p}<0.004)^{\mathrm{b}}$ & & $73.2 \%$ & $259(23.6 \%)$ & $473(39.2 \%)$ & $365(31.5 \%)$ \\
\hline
\end{tabular}

DHG $=$ Dyshormonogenetic glands (usually enlarged but eutopic).

${ }^{\mathrm{a}}$ Rectilinear scan. ${ }^{\mathrm{b}} \chi^{2}$ test.

\section{Imaging of Dysplastic Thyroid Tissue}

TD includes a spectrum of embryogenic defects such as athyrosis, hypoplasia, hemiagenesis, ectopic thyroid gland and thyroglossal duct cysts. A genetic origin for TD is suspected though the molecular defects have only been identified in a few patients. Three main genes involved in the thyroid development and in the transcriptional control of the genes encoding the thyroid-specific proteins have been identified: the thyroid transcription factors TTF1 and TTF2, and Pax 8 [20]. These genes are frequently involved in different complex syndromes including $\mathrm{CH}$ due to TD [21]. On the other hand, homozygous or compound heterozygous inactivating mutations in the $\mathrm{R}$-TSH have been observed in patients with non-syndromic $\mathrm{CH}$ due to thyroid hypoplasia and various degrees of TSH unresponsiveness. Finally, TD is likely to be a polygenic and multifactorial disease for which novel genes need to be identified [22].

\section{Ectopic Tissue}

${ }^{123}$ I TS is the gold standard method for assessing the diagnosis of ectopic thyroid tissue [23], the most frequent aetiology for dysplasia (fig. 2). Ectopic tissue can be clas- sified as lingual thyroid, which may sometimes be visible or palpable [24], or as tissue in a suprahyoid, hyoid or infrahyoid location. The incidence of double ectopic thyroid is about $5 \%$. TS indicates in addition whether normally functioning tissue is present or not in the normal cervical location. Indeed, ectopic glands are functional and their inadvertent surgical removal, if it is misdiagnosed as a thyroglossal duct cyst, results in iatrogenic hypothyroidism.

It is widely accepted that CDU is slightly less sensitive than TS in children with $\mathrm{CH}$ [25]. The agreement between the two methods was 0.87 in one recent study [26], though large variations are reported in the literature, probably because the reproducibility of CDU strongly depends on the physician's experience and on the generation of the apparatus used. For instance, it has been shown that grey-scaled ultrasound are $20 \%$ less sensitive than $\mathrm{CDU}$ in detecting ectopic tissue [27]. CDU generally succeeds in determining whether the thyroid is eutopic or dysplastic, but regularly fails to distinguish athyrotic glands from ectopic ones. Finally, in the literature, routine CDU has a wide range of sensitivity (range: 0-90\%) in the detection of ectopic thyroid tissue, though higher 

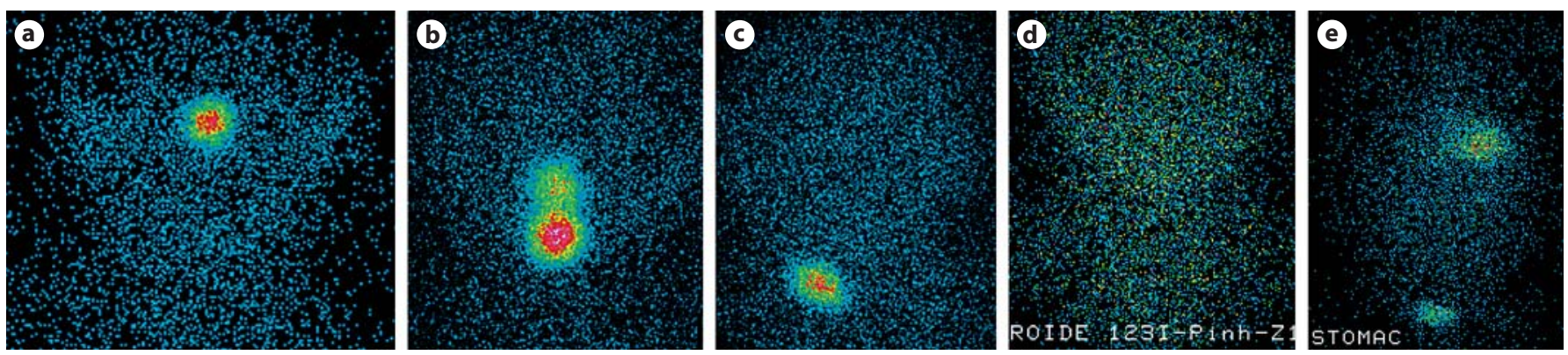

Fig. 2. Scintigraphic imaging of dysplastic thyroid tissue $\left({ }^{123} \mathrm{I}\right)$ (frontal view). a Median solitary lingual ectopia; note the faint uptake of the salivary gland and the low activity of the mouth due to the use of ${ }^{123} \mathrm{I}$. $\mathbf{b}$ Double ectopic thyroid with no activity in normal location; the upper is suprahyoidal while the lower is prehyoidal. c Agenesis of the left lobe. d Absence of contrast in the neck in a baby with athyrosis. Note that the gastric ${ }^{123} \mathrm{I}$ image is positive (e), excluding an NIS defect; in addition, no significant activity is visible in the mouth using intravenous ${ }^{123} \mathrm{I}$.

values $(>80 \%)$ have been regularly reported in recent papers $[28,29]$. When a eutopic goitre is disclosed with CDU, ${ }^{123}$ I TS is nevertheless useful to classify the location of the defect and to provide information on the potential reversibility of hypothyroidism.

\section{Athyrotic and Hypoplastic Glands}

Thyroid aplasia should be considered when no significant uptake appears on the scan, with a field of view including the neck and the head, and late images when ${ }^{123} \mathrm{I}$ is used. A lingual thyroid may be masked by the mouth activity with ${ }^{99} \mathrm{TcO}_{4}$ and this may lead to erroneously diagnose thyroid aplasia. Hypoplastic glands usually have a modified shape - round-shaped lobes, uniloby or asymmetry in the location of the lobes - and an inappropriately low contrast or uptake using TS. CDU can theoretically measure a reduced glandular volume (normal values in neonates: $0.7-2.3 \mathrm{ml}$ ). In fact, CDU and TS are complementary techniques for the characterization of these conditions [30]. Indeed, false-positive and falsenegative imaging results are regularly reported when a single method is used. Orthotopic glands have been described by ultrasounds when scintigraphy suggested athyrosis and conversely 'hypoplastic glands' have been reported in babies with normal-shaped glands and ${ }^{123} \mathrm{I}$ uptake measurements [31].

\section{Hemiagenesis}

Thyroid hemiagenesis is a rare condition, with a prevalence of about $0.05 \%$ in unselected teenagers and should be considered when thyroid tissue cannot be found by palpation especially at the left side of the neck [32]. Indeed, the left lobe is absent (fig. 2) in at least $80 \%$ of the cases with no visibility of the isthmus in 50\%. Most of the time the thyroid function is normal, though rarely congenital or late onset hypothyroidism has been reported. CDU demonstrates a single lobe of variable volume and echogenicity. TS is also helpful to evaluate the glandular function and to occasionally reveal ectopic thyroid tissue [33]. Any pathological condition may also occur in the remaining lobe.

\section{Thyroid Scan Imaging of Thyroid DHG}

DHG accounts for about $10 \%$ of cases of $\mathrm{CH}$ and reflects a defect in any of the steps in thyroid hormone synthesis $[34,35]$. As a general rule, these defects are responsible for a corresponding rise in the plasma thyrotropin level causing a diffuse goitre which may over time become multinodular. In figure 3 we give a schematic description of the iodide atom journey from its uptake by the NIS to its release as $T_{4} / T_{3}$ by the thyrocyte into the bloodstream. This approach makes it possible to provide a functional ${ }^{123}$ I TS-based classification of DHG (fig. 3) and explains the scintigraphic patterns (fig. 4).

\section{Defective NIS}

Though uncommon, a few individuals have been identified for several homozygous or compound heterozygous mutations in the NIS, responsible for impaired iodide uptake [36,37]. This loss of function is systemic and also involves normal iodide salivary excretion and stomach uptake (fig. 4). A eutopic goitre is present and often palpable. The ${ }^{123}$ I TS shows no or only faint thyroid contrast with a ${ }^{123}$ I uptake measurement of below $4 \%$ even with a 24 -hour image. The ${ }^{123} \mathrm{I}$ gastric image shows no 


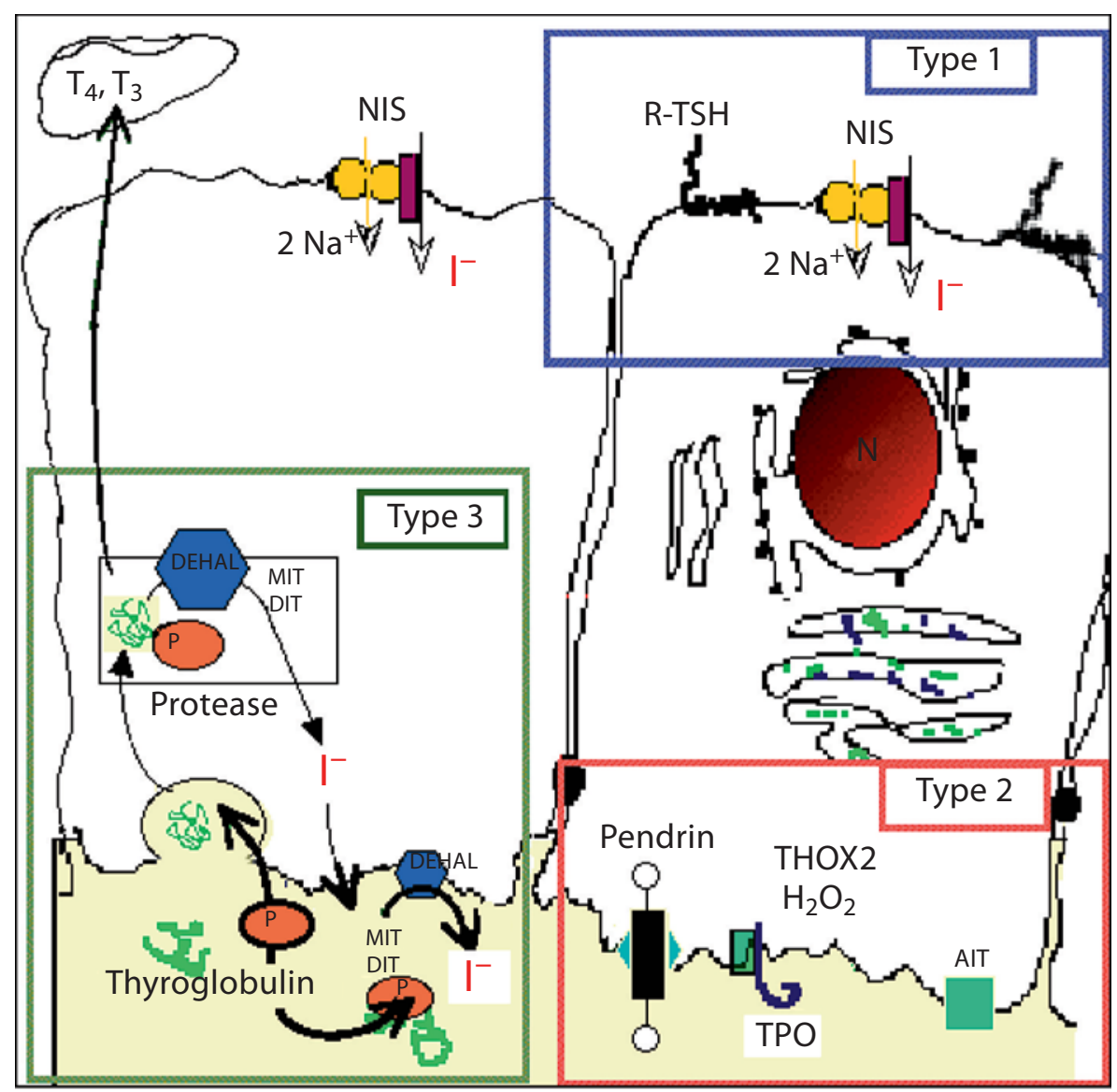

Fig. 3. Scintigraphic-based classification of thyroid DHG. Type 1 (impaired function at the basal membrane) defects are characterized by low to blunted contrast despite high TSH plasma levels. Late ${ }^{123} \mathrm{I}$ images are more often positive than ${ }^{99 \mathrm{~m}} \mathrm{Tc}$ images. Defective R-TSH is often associated with thyroid hypoplasia or reflects a transient blockade of the thyrotropin receptor by maternal autoantibodies. Defective or abnormal NIS yields no uptake either at the thyroid and stomach level. Type 2 defects (impaired function at the apical membrane) are responsible for a reduced iodide organification. Both scintigraphic contrast and uptake are high and rise quickly in an enlarged thyroid. The perchlorate discharge test is positive with a washout value $>10 \%(>50 \%)$ in partial (complete) organification defect, respectively. Complete organifica- tion defects are most often due to a mutation in the TPO gene. Partial defects occur in minor TPO abnormalities and in Pendred syndrome (abnormal pendrin). In rare cases, the peroxide generator is involved due to a mutation in the THOX gene. Type 3 defects (postorganification defects) include a goitre with preserved uptake and a normal organification process (negative perchlorate discharge test). Indeed, iodide which has entered the organification process cannot be chemically displaced by perchlorate. Mutations in the Tg gene are relatively frequent compared to other abnormalities such as defective pinocytic resorption of the $\mathrm{Tg}$. Finally, DEHAL1 produce a secondary iodine-deficient state due to excessive renal losses of iodine in the form of MIT and DIT. contrast in defective NIS babies provided the isotope has been previously injected. Finally, the ${ }^{123}$ I measurement of the salivary-to-plasma ratio activity is decreased $(\mathrm{S} / \mathrm{P}<1$, normal values: $S / P>10$ ), while plasmatic $\mathrm{Tg}$ levels are usually normal or even high [38].

\section{Defective R-TSH}

Diagnosis of TSH unresponsiveness in babies with $\mathrm{CH}$ is suspected by imaging when a hypoplastic or non-goi- trous eutopic thyroid gland with low thyroidal ${ }^{123}$ I uptake is evidenced in the absence of thyroid autoantibodies [39]. Due to the lower signal-to-noise ratio observed with ${ }^{99 \mathrm{~m}} \mathrm{Tc}$, the ${ }^{99 \mathrm{~m}} \mathrm{Tc} \mathrm{TS}$ may indicate a false-negative result of athyrosis [40]. The TSH, when tested in vitro, has a normal bioactivity. The biochemical phenotype includes a moderate to high rise in the plasma TSH levels, normal to blunted thyroid hormone levels and detectable Tg levels. When the gland is orthotopic, a partial resistance to 
Fig. 4. Imaging of thyroid DHG. a-c NIS defect in a boy with a small goitre. The ${ }^{123} \mathrm{I}$ TS (a) shows no significant uptake in the neck and the head and an absence of ${ }^{123} \mathrm{I}$ contrast in the stomach in the anterior abdominal view (b). c A small dose of ${ }^{99 \mathrm{~m}} \mathrm{Tc}$ was finally given per os and readily permitted the stomach to be imaged. Organification defect presents with goitre and high early uptake sensitive to perchlorate. d, e Complete organification defect; thyroid counts were reduced by $83 \%$ suggesting a defective TPO gene. f, $\mathbf{g}$ The perchlorate was unable to displace organified ${ }^{123} \mathrm{I}$ from the colloidal compartment (discharge of below $3 \%$ ), suggesting a type 3 defect.
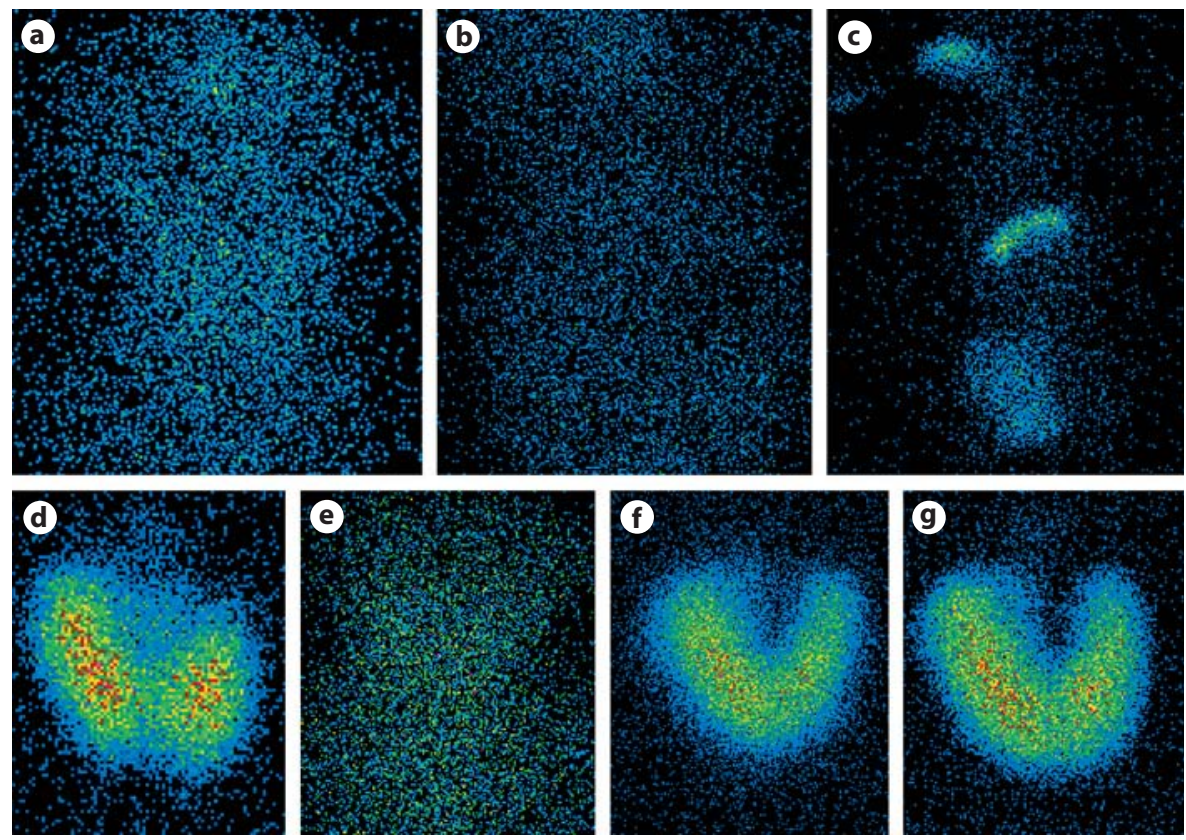

TSH or euthyroid hyperthyrotopinaemia [41] must be suspected especially when both the thyroxine levels and the ${ }^{123}$ I uptake are normal.

\section{Organification Defects}

Transport of iodide towards the apical membrane follows the electrochemical gradient and is a rapid phenomenon for which no abnormality has yet been evidenced. Iodination of tyrosine residues and further coupling of iodinated tyrosines to generate thyroxine and/or triiodothyronine depend on the critical glycosylated enzyme thyroperoxidase (TPO). A mutation in the TPO gene is the most frequent molecular abnormality $(>70 \%)$ causing a partial or total organification defect [42]. In the latter, an inactivation mutation of the TPO gene is almost always present. A few patients with goitre, reduced iodine organification and eu- or hypothyroidism, have defective $\mathrm{H}_{2} \mathrm{O}_{2}$ generation and mutations in the NADPH oxidase gene encoding THOX2 [43].

Any pathological process which affects iodide efflux, or iodination and coupling of iodide onto the tyrosyl residues of the Tg can be scintigraphically characterized by a strong early TSH-related uptake, followed by a quantifiable fall in previously taken up ${ }^{123} \mathrm{I}$ after perchlorate administration. Indeed, once organified, ${ }^{123} \mathrm{I}$ is insensitive to perchlorate which only acts as an extracellular selective inhibitor for de novo isotopic uptake at the NIS level.
Efflux of iodide at the apical membrane of thyroid follicular cells is mediated by pendrin and marginally by hAIT, a recently identified apical iodine transporter. $\mathrm{Mu}-$ tations in the pendrin gene [44] cause Pendred's syndrome, clinically defined by the association of goitre, partial or complete inability to organify iodine and sensorineural deafness. An additional advantage for checking neonates and infants with goitres using ${ }^{123} \mathrm{I}$ TS is that many Pendred patients do not present with $\mathrm{CH}$ and that the development of hypothyroidism is far from being systematic, especially in iodine-replete areas.

\section{Dyshormonogenetic Eutopic Glands with Normal \\ Organification}

When goitre is present and if the TS is well contrasted and insensitive to perchlorate administration, the functional integrity of R-TSH, NIS, TPO, THOX and Pendrin proteins can be assumed. The following abnormalities may finally be taken into consideration: (1) reduced or abnormal Tg synthesis [45], which is the most frequent cause [35], (2) impaired colloidal resorption or Tg proteolysis [46], and (3) reduced deiodination process of the iodotyrosines MIT and DIT involving disorders of the DEHAL1 system [12]. In this latter the iodine uptake and turnover are further stimulated by a secondary iodinedeficient state due to excessive renal losses of iode in the form of MIT and DIT. A reliable 'deiodination' test had been used by injecting labelled DIT $\left({ }^{123} \mathrm{I} /{ }^{125} \mathrm{I} /{ }^{131} \mathrm{I}\right)$ to fur- 
ther measure its urinary excretion [47], which was abnormally high in defective DEHAL1 patients (urinary labelled DIT $>95 \%$ of the injected compound) as compared to controls $(<15 \%)$, but this tracer is no longer available in most countries. In this group of diseases, the metabolic status varies with the severity of the defect and goitre is usually present but not constant. Many patients with minor abnormalities may present with normal phenotypes or transient hypothyroidism and no specific diagnosis will be made. They are at risk of developing a goitre or late-onset hypothyroidism in some circumstances such as puberty, pregnancy or reduced nutritional iodine intake. In children with a thyroid of normal size and shape, other diagnoses should be considered such as Down's syndrome and pseudohypoparathyroidism, though the aetiology cannot always be determined.

\section{Imaging of Transient and Acquired Hypothyroidism in Childhood}

Most transient disorders occur in babies or in the prenatal period and are relatively uncommon after 1 year of age. After 10, these disorders have the same aetiology as found in adults [48]. Chronic lymphocytic thyroiditis is the most frequent cause in iodine-replete areas. This is often asymptomatic or associated with goitre (Hashimoto's strumitis) and is more frequent in patients with other endocrine deficiencies of autoimmune origin such as type 1 diabetes.

The frequency of transient hypothyroidism is not well known because in many cases the dysfunction is mild and resolves rapidly, so that the precise aetiology is not established. In a recent paper dealing with $\mathrm{CH}$ in a normally located gland, $38 \%$ were identified as having transient hypothyroidism [3]. Risk factors for transient hypothyroidism are prematurity, iodine overload, maternal thyroid autoimmunity and ectopic gland. A frequent presentation is iodine overload secondary to maternal skin disinfection with polyvidone when an obstetrical procedure, Caesarean or episotomy, is indicated. Typically, the baby presents with a goitre, high ${ }^{123} \mathrm{I}$ uptake and a positive perchlorate discharge test. Significant iodine overload, as assessed in babies by a urinary excretion of over $100 \mu \mathrm{g} /$ day, may induce a physiological organification blockade which may persist for several days or weeks after iodine exposure, especially in immature glands, in patients with lymphocytic thyroiditis and in countries with high iodine intakes. The high thyroidal isotopic uptake despite hypothyroidism indicates essentially normal glandular tissue and is predictive of a reversible disorder, even in older patients and adults [49].

Maternal-mediated transient hypothyroidism due to a thyrotropin receptor blocking antibody (TRb-AB) accounts for about $2 \%$ of $\mathrm{CH}$ [50]. An evolutionary or past history of thyroid autoimmune disease in the mother is present. The maternal plasmatic TRb-AB levels must be measured to assess the diagnosis. Imaging is not mandatory. CDU scanning would show a normal or hypoplastic gland with normal or decreased vascularization and the TS a blunted ${ }^{123}$ I uptake. The hypothyroidism resolves over 3-6 months as the maternal TRb-AB disappears from the infant's circulation.

\section{Imaging of Thyrotoxicosis}

Most paediatric patients with thyrotoxicosis have autoimmune thyroid diseases, mainly ( $>95 \%$ ) Graves' disease. However the incidence of thyrotoxicosis in children is relatively low as compared to adulthood, since less than $5 \%$ of thyroid disease with thyrotoxicois begins before the age of 16 [9]. The incidence rises from $0.1 / 100,000$ in young children to $3 / 100,000$ in adolescence [51] and is more frequent in females with sex ratios of 3:1 to 5:1. Thyrotoxicosis may be transient especially in neonates or permanent in patients with activating mutations of the TSH receptor or of the Gs $\alpha$ subunit and grossly have the same aetiology in adolescence and in adults.

\section{Imaging of Transient Thyrotoxicosis}

In neonates, thyrotoxicosis is most often due to a transplacental passage of thyroid-stimulating immunoglobulins (TSI) present in the maternal blood. The prevalence of autoimmune neonatal thyrotoxicosis widely varies in the literature. Indeed, it is estimated that $0.1-$ $0.4 \%$ of pregnant women have Graves' disease. However, the frequency of neonatal thyrotoxicosis in the offspring of these mothers with autoimmune thyroid disease has been reported with values ranging between 0.6 and $9.6 \%$ [52]. TSI are obviously present in active maternal Graves' disease but they may persist for years after diagnosis or ${ }^{131}$ I therapy. This transient cause of thyrotoxicosis usually resolves within 3-20 weeks.

Late-onset $(>1$ week) neonatal thyrotoxicosis may occur when a mixture of TRb-AB and TSI is present in the maternal blood. CDU is helpful, showing a goitre with normal or hypoechoic structure, increased tissue vascularization and accelerated blood flow in the inferior thyroid arteries. 
Fig. 5. Imaging of thyrotoxicosis: autoimmunity. a Graves' disease is evidenced by high early uptake despite blunted TSH, diffuse and homogeneous contrast. b Ultrasound may be suggestive showing a diffusely hypervascular parenchyma and high blood speed in the thyroidal arteries. c Often the ${ }^{123} \mathrm{I}$ scan reveals a mixed Graves'-Hashimoto's strumitis with lower though inappropriate uptake values and diffuse but heterogeneous contrast. d Ultrasounds are not specific and show a hypoechoic pattern and/or pseudonodules. Incidental true nodules can also be evidenced.

Fig. 6. Imaging of thyrotoxicosis: autonomy. Unifocal autonomy (a) as well as multifocal autonomy (mutations in the R-TSH receptor) are quite rare before the age of 10 years. The autonomous nodule is hyperfunctioning on the scan (baseline) and its contrast cannot be suppressed by exogenous $\mathrm{IT}_{3}$ administration (same patient; $\mathrm{T} 3$ suppression test) (b). It grows slowly to toxicity with an incidence of $4 \%$ per year. Typically the nodule is hypervascularized (type 3 Doppler pattern, as shown in c). Before the age of 10 years, nodular thyrotoxicosis may be due to the McCune-Albright syndrome (activation of the Gs $\alpha$ ). The ${ }^{123} \mathrm{I}$ uptake is moderately elevated and the contrast is enhanced diffusely or focally despite blunted TSH levels (d). CDU scanning pattern shows diffuse hypoechogenic images with hypervascularization (e).
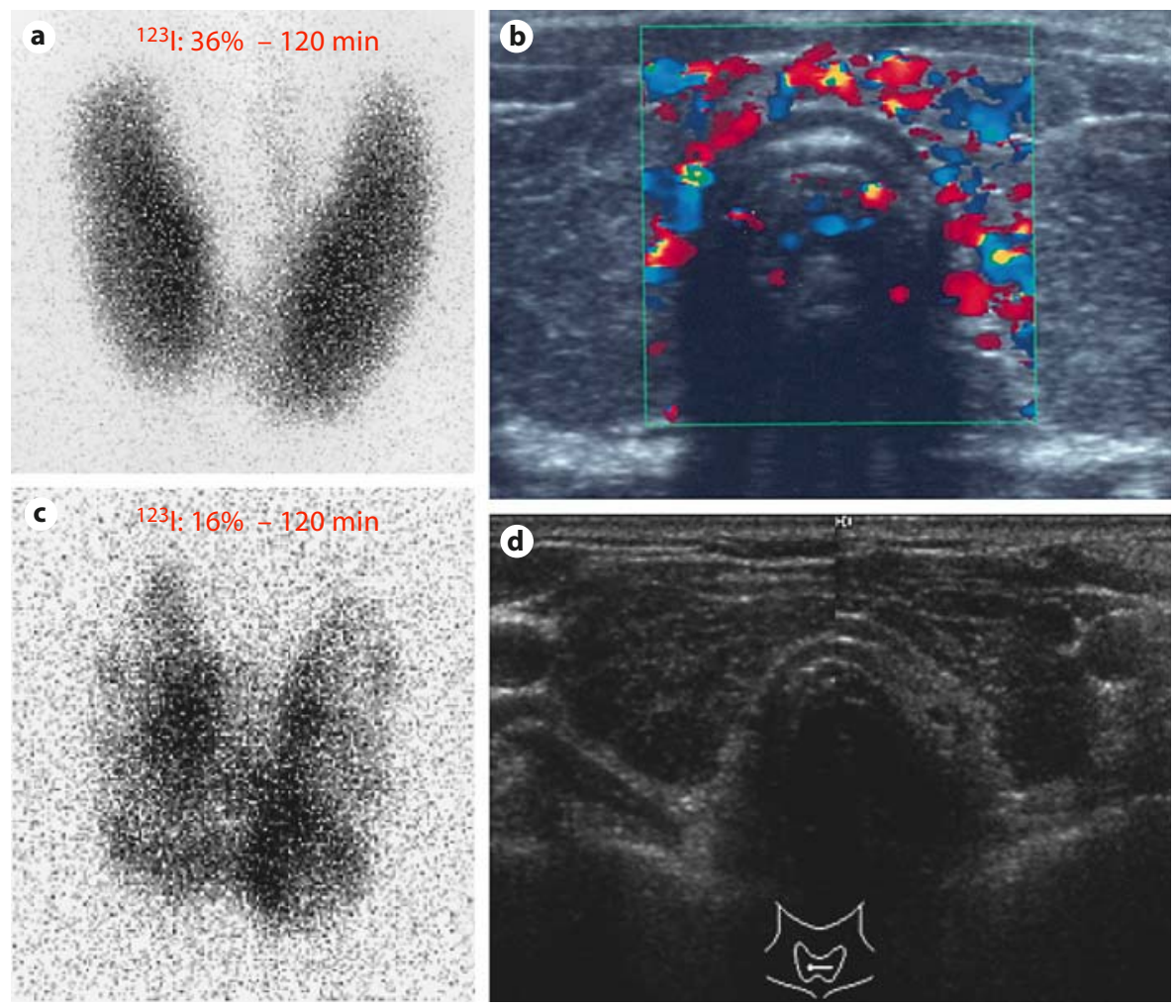
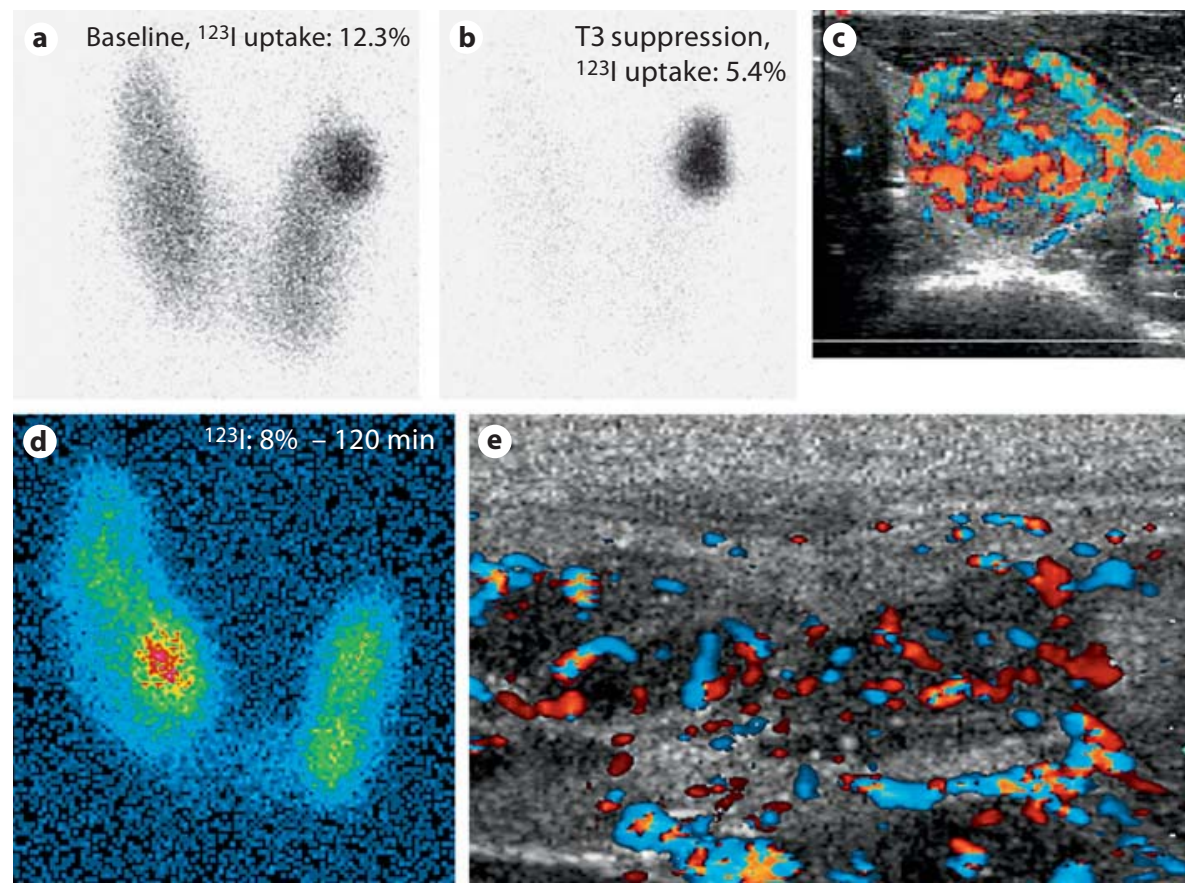
Table 4. Main thyroid imaging features according to paediatric aetiology of thyrotoxicosis

\begin{tabular}{|c|c|c|c|c|}
\hline \multirow[t]{2}{*}{ Etiology } & \multicolumn{2}{|l|}{ Thyroid scan } & \multirow[t]{2}{*}{ Ultrasound } & \multirow[t]{2}{*}{ Other features } \\
\hline & contrast & uptake & & \\
\hline Congenital Graves' disease & diffuse, homoG & $\Uparrow++$ & hypervascular goitre & transient - US as 1st line \\
\hline Acquired Graves' disease & diffuse, homoG & $\Uparrow++$ & hypervascular goitre & rare $<10$ years, TSI ++ \\
\hline Mixed Graves'-Hashimoto & diffuse, heteroG & $\Uparrow+$ & idem, hypoechoic & rare $<10$ years, TSI + \\
\hline Iatrogenic (thyroxine) & unnecessary & & unnecessary & reduce $\mathrm{T}_{4}$ dosage \\
\hline Familial toxic hyperplasia & diffuse, homoG & $\Uparrow$ & hypervascular goitre & germline mut. RTSH \\
\hline McCune-Albright syndrome & multifocally $\Uparrow$ & $\Uparrow$ & hypervascular goitre & mut. GS $\alpha$ \\
\hline Mono (multi)-focal autonomy & mono/multifocally & $\Uparrow$ & nodular vascularization & mut. RTSH (acquired) \\
\hline Thyroiditis (all types) ${ }^{\mathrm{a}}$ & low to 0 & $\Downarrow$ & hypoechoic & transient \\
\hline
\end{tabular}

homoG = Homogeneous pattern; US = ultrasound; TSI = thyroid-stimulating immunoglobulins; heteroG = heterogeneous; mut. $\mathrm{RTSH}=$ gain of function mutation of the TSH receptor.

a Aetiology for thyroiditis includes subacute (viral related), iodine-induced, postirradiation (X, gamma or electronic), immunogenic, cytokine-induced.

Imaging of Permanent and Acquired Thyrotoxicosis

After the age of 10 years, thyrotoxicosis is generally due to Graves' disease or to forms related to Hashimoto's strumitis, the latter giving a diffuse though heterogeneous pattern of uptake (fig. 5) with intermediate ${ }^{123}$ I uptake values (15-25\%), as in adults. The other various causes can also be encountered at this age and have no special imaging features as compared to adults (table 4).

Resistance to thyroid hormone must be taken into consideration when the neonatal screening shows mildly persistent increased TSH levels or later when elevated free hormones are measured in the presence of a non-suppressed TSH. This rare disease has a widely variable phenotypic expression which can include a goitre and mild thyrotoxicosis. The thyroid gland is inappropriately overstimulated by the TSH and the thyroid scan mimics Graves' disease though the biochemical context excludes any autoimmune origin.

The differential diagnosis in babies with persistent non-autoimmune thyrotoxicosis is the rare germline-activating mutation of the TSH receptor [53] and nodular thyrotoxicosis of the McCune-Albright syndrome (fig. 6). A diffuse homogeneous uptake and an enlarged gland were reported on a ${ }^{99 \mathrm{~m}} \mathrm{Tc}$ TS of a boy with familial toxic diffuse hyperplasia [54]. Though in Graves' disease typically high early ${ }^{123}$ I uptake is expected (15-50\%), lower values are suggestive of autonomy (5-15\%). This is the case in the McCune-Albright syndrome (Gs $\alpha$ mutation), where diffuse or multifocal autonomy is typically imaged by the ${ }^{123} \mathrm{I}$ TS. The nodules share the same hypervascularized pattern as in classic autonomously functioning nodules (R-TSH mutation), which are uncommon before the age of 10 years.

In conclusion, imaging of thyroid dysfunction in neonates and babies is very safe and clinically relevant. Both thyroid scan and CDU are useful and complementary, as in adults and for many authors combined imaging appears more informative than single scanning. A precise knowledge of the underlying disease may help to manage the therapy and optimize genetic counselling. Permanent hypothyroidism is mainly due to thyroid ectopia, hypoplasia and less frequently DHG. Transient hypothyroidism is probably underdiagnosed and its identification is warranted since it permits the discontinuation of $\mathrm{IT}_{4}$ therapy. Though ${ }^{99} \mathrm{mcO}_{4}$ often provides a correct diagnosis, most recent publications show that ${ }^{123} \mathrm{I}$ TS is the best nuclear medicine procedure. Indeed, the use of ${ }^{123} \mathrm{I}$ yields a higher accuracy for the detection of ectopic glands and has a higher detection rate for eutopic glands, for which transient hypothyroidism is relatively frequent. CDU is increasingly used but demands a skilled physician to guarantee a good imaging quality. It is especially useful in normally located glands and may reveal additional information regarding the anatomy of the gland, its vascularization and the presence of nodules. Imaging patterns of autoimmune thyrotoxicosis are very similar to those observed in adults. CDU is the procedure of choice in imaging neonatal thyrotoxicosis. Nodular thyrotoxicosis should be imaged by a ${ }^{123}$ I TS and may be suggestive of a McCune-Albright syndrome in younger patients. 


\section{References}

1 Connelly JF, Coakley JC, Gold H, Francis I, Mathur KS, Rickards AL, Price GJ, Halliday JL, Wolfe R: Newborn screening for congenital hypothyroidism, Victoria, Australia, 1977-1997. Part 1. The screening programme, demography, baseline perinatal data and diagnostic classification. J Pediatr Endocrinol Metab 2001;14:1597-1610.

2 La Franchi S: Congenital hypothyroidism: etiologies, diagnosis and management. Thyroid 1999;9:735-740.

3 Gaudino R, Garel C, Czernichow P, Leger J: Proportion of various types of thyroid disorders among newborns with congenital hypothyroidism and normally located gland: a regional cohort study. Clin Endocrinol (Oxf) 2005;62:444-448.

4 Rovet JF: Congenital hypothyroidism: long term outcome. Thyroid 1999;9:741-748.

$5 \mathrm{Ng} \mathrm{SM}$, Wong SC, Isherwood DM, Smith CS, Didi M: Multivariate analysis on factors affecting suppression of thyroid-stimulating hormone in treated congenital hypothyroidism. Horm Res 2004;62:245-251.

-6 Sfakianakis GN, Ezuddin SH, Sanchez JE, Eidson M, Cleveland W: Pertechnetate scintigraphy in primary congenital hypothyroidism. J Nucl Med 1999;40:799-804.

7 Kopp P: Perspective: genetic defects in the etiology of congenital hypothyroidism. Endocrinology 2002;143:2019-2024.

8 Gillam MP, Kopp P: Genetic regulation of thyroid development. Curr Opin Pediatr 2001;13:358-363.

9 Bettendorf M: Thyroid disorders in children from birth to adolescence. Eur J Nucl Med 2002;29(suppl 2):S439-S446.

10 Heyman S: Thyroidal uptake of iodine-123 in children using a gamma camera and computer. Clin Nucl Med 1985;10:690-693.

11 Zanzonico PB: Age-dependent thyroid absorbed doses for radiobiologically significant radioisotopes of iodine. Health Phys 2000;78:60-67.

12 Gnidehou S, Caillou B, Talbot M, Ohayon R, Kaniewski J, Noël-Hudson MS, Morand S, Agnangii D, Sezan A, Courtin F, Virion A, Dupuy C: Iodotyrosine dehalogenase 1 (DEHAL1) is a transmembrane protein involved in the recycling of iodide close to the thyroglobuline iodination site. FASEB J 2004;18: 1574-1576.

13 Hilditch TE, Jackson HJ: Quantitative ${ }^{123} \mathrm{I}-$ iodide scintigraphy and radiation dosimetry in infants with congenital hypothyroidism. Eur J Nucl Med 1985;11:132-135.

- 14 Bubuteishvili L, Garel C, Czernichow P, Leger J: Thyroid abnormalities by ultrasonography in neonates with congenital hypothyroidism. J Pediatr 2003;143:759-764.
15 Pusuwan P, Likitmaskul S, Wacharasindhu S, Intarasupht S, Attanatho V, Mungkharak J, Chiewvit S, Pleehachinda R: Thyroid scintigraphy in children with hypothyroidism: a five-year experience. J Med Assoc Thai 1998; 81:596-601.

16 el-Desouki M, al-Jurayyan N, al-Nuaim A al-Herbish A, Abo-Bakr A, al-Mazrou Y, alSwailem A: Thyroid scintigraphy and perchlorate discharge test in the diagnosis of congenital hypothyroidism. Eur J Nucl Med 1995;22:1005-1008.

17 Panoutsopoulos G, Mengreli C, Ilias I, Batsakis C, Christakopoulou I: Scintigraphic evaluation of primary congenital hypothyroidism: results of the Greek screening program. Eur J Nucl Med 2001;28:529-533.

18 Shapiro B, Britton K, Fountos A, Granowska M, Hawkins L, Kiriaki P, Londres S, Nimmon C, Poston S: A multiobserver comparison of ${ }^{99 \mathrm{~m}} \mathrm{TcO}_{4}$ and ${ }^{123} \mathrm{I}$ thyroid imaging. Eur J Nucl Med 1981;6:135-138.

19 Schoen EJ, Clapp W, To TT, Fireman BH: The key role of newborn thyroid scintigraphy with isotopic iodide $\left({ }^{123} \mathrm{I}\right)$ in defining and managing congenital hypothyroidism. Pediatrics 2004; 114:e683-e688.

20 Park SM, Chatterjee VKK: Genetics of congenital hypothyroidism. J Med Genet 2005; 42:379-389.

-21 Grüters A, Krude H, Biebermann H: Molecular genetic defects in congenital hypothyroidism. Eur J Endocrinol 2004;151(suppl 3): U39-U44.

22 Castanet M, Sura-Trueba S, Chauty A, Carre A, de Roux N, Heath S, Leger J, Lyonnet S, Czernichow P, Polak M: Linkage and mutational analysis of familial thyroid dysgenesis demonstrate genetic heterogeneity implicating novel genes. Eur J Hum Genet 2005; 13 . 232-239.

23 Verelst J, Chanoine JP, Delange F: Radionuclide imaging in primary permanent congenital hypothyroidism. Clin Nucl Med 1991;16:652-655.

24 Arancibia P, Veliz J, Barria M, Pineda G: Lingual thyroid: report of three cases. Thyroid 1998;8:1055-1057.

25 De Bruyn R, Ng WK, Taylor J, Campbell F, Mitton SG, Dicks-Mireaux C, Grant DB: Neonatal hypothyroidism: comparison of radioisotope and ultrasound imaging in 54 cases. Acta Paediatr Scand 1990;79:11941198.

-26 Kreisner E, Camargo-Neto E, Maia CR, Gross JL: Accuracy of ultrasonography to establish the diagnosis and aetiology of permanent primary congenital hypothyroidism Clin Endocrinol (Oxf) 2003;59:361-365.

$\checkmark 27$ Ohnishi H, Sato H, Noda H, Inomata H, Sasaki N: Color Doppler ultrasonography: diagnosis of ectopic thyroid gland in patients with congenital hypothyroidism caused by thyroid dysgenesis. J Clin Endocrinol Metab 2003;88:5145-5149.
28 Takashima S, Nomura N, Tanaka H, Itoh Y, Miki K, Harada T: Congenital hypothyroidism: assessment with ultrasound. AJNR Am J Neuroradiol Roentgenol 1995;16:11171123.

-29 Niu DM, Chao T, Tiu CM, Chou YH, Chu YK, Hwang B: Comparison of radioisotopic and ultrasonic scanning in the evaluation of neonatal hypothyroidism. Zhonghua Yi Xue Za Zhi (Taipei) 1995;56:345-350.

-30 Perry RJ, Maroo S, Maclennan AC, Jones JH, Donaldson MD: Combined ultrasound and isotope scanning is more informative in the diagnosis of congenital hypothyroidism than simple scanning. Arch Dis Child 2006; 91:972-997.

-31 Meller J, Zappel H, Conrad M, Roth C, Emrich $\mathrm{D}$, Becker W: ${ }^{123} \mathrm{I}$-scintigraphy and perchlorate depletion test in the diagnosis of congenital hypothyroidism. Nuklearmedizin 1998;37:7-11.

\32 Maiorana R, Carta A, Floriddia G, Leonardi D, Buscema M, Sava L, Calaciura F, Vigneri R: Thyroid hemiagenesis: prevalence in normal children and effect on thyroid function. J Clin Endocrinol Metab 2003;88:15341536.

33 Bergami G, Barbuti D, Di Mario M: Echographic diagnosis of thyroid hemiagenesis. Minerva Endocrinol 1995;20:195-198.

34 de Vijlder JJ: Primary congenital hypothyroidism: defects in iodine pathways. Eur J Endocrinol 2003;149:247-256.

>35 Lever EG, Medeiros-Neto GA, DeGroot LJ: Inherited disorders of thyroid metabolism. Endocr Rev 1983;4:213-239.

36 Leger DA, Doumith R, Courpotin C, Helal B, Davous N, Aurengo A: Complete iodine trapping defect in two cases with congenital hypothyoidism: adaptation to huge iodide supplementation. Eur J Clin Invest 1987;17: 249-255.

>37 Szinnai G, Kosuhi S, Derrien C, Lucidarme N, David V, Czernichow P, Polak M: Extending the clinical heterogeneity of iodide transport defect (ITD): a novel mutation R124H of the sodium/iodide symporter gene and review of genotype-phenotype correlations in ITD. J Clin Endocrinol Metab 2006;91:11991204.

38 Vulsma T, Rammeloo JA, Gons MH, de Vijlder JJ: The role of serum thyroglobulin concentration and thyroid ultrasound imaging in the detection of iodide transport defects in infants. Acta Endocrinol (Copenh) 1991;124:405-410

-39 Takeshita A, Nagayama Y, Yamashita S, Takamatsu J, Ohsawa N, Maesaka H, Tachibana K, Tokuhiro E, Ashizawa K, Yokoyama N, et al: Sequence analysis of the thyrotropin (TSH) receptor gene in congenital primary hypothyroidism associated with TSH unresponsiveness. Thyroid 1994;4: 255-259. 
40 Gagne N, Parma J, Deal C, Vassart G, Van Vliet G: Apparent congenital athyreosis contrasting with normal plasma thyroglobulin levels and associated with inactivating mutations in the thyrotropin receptor gene: are athyreosis and ectopic thyroid distinct entities? J Clin Endocrinol Metab 1998;83:17711775.

41 Sunthornthepvarakui T, Gottschalk ME, Hayashi Y, Refetoff S: Brief report: resistance to thyrotropin caused by mutations in the thyrotropin-receptor gene. N Engl J Med 1995;332:155-160.

-42 Medeiros-Neto GA, Billerbeck AE, Wajchenberg BL, Targovnik HM: Defective organification of iodide causing hereditary goitrous hypothyroidism. Thyroid 1993;3:143-159.

-43 Moreno JC, Bikker H, Kempers MJ, van Trotsenburg AS, Baas F, de Vijlder JJ, Vulsma $\mathrm{T}$, Ris-Stalpers $\mathrm{C}$ : Inactivating mutations in the gene for thyroid oxidase 2 (THOX2) and congenital hypothyroidism. N Engl J Med 2002;347:95-102.

44 Sheffield VC, Kraiem Z, Beck JC, Nishimura D, Stone EM, Salameh M, Sadeh O, Glaser B: Pendred syndrome maps to chromosome $7 q 21-34$ and is caused by an intrinsic defect in thyroid iodine organification. Nat Genet 1996;12:424-426.
45 Vono-Toniolo J, Rivolta CM, Targovnik HM, Medeiros-Neto G, Kopp P: Naturally occurring mutations in the thyroglobulin gene. Thyroid 2005;15:1021-1033.

46 Tepel C, Bromme D, Herzog V, Brix K: Cathepsin $\mathrm{K}$ in thyroid epithelial cells: sequence, localization and possible function in extracellular proteolysis of thyroglobulin. J Cell Sci 2000;113:4487-4498.

47 Aurengo A, Savoie F, Leger AF, Savoie JC: Would I-123 di-iodotyrosine provide a harmless deiodination test? Concise communication. J Nucl Med 1983;24:1143-1148.

48 Hunter I, Green SA, McDonald T, Morris AD: Prevalence and aetiology of hypothyroidism in the young. Arch Dis Child 2000; 83:207-210.

49 Okamura K, Sato K, Ikenoue H, Yoshinari M, Nakagawa M, Kuroda T, Fujishima M Reevaluation of the thyroidal radioactive iodine uptake test, with special reference to reversible primary hypothyroidism with elevated thyroid radioiodine uptake. J Clin Endocrinol Metab 1988;67:720-726.
50 Brown S, Bellisario RL, Botero D, Fournier L, Abrams CA, Cowger ML, David R, Fort P, Richman RA: Incidence of transient congenital hypothyroidism due to maternal thyrotropin receptor-blocking antibodies in over one million babies. J Clin Endocrinol Metab 1996;81:1147-1151.

51 Birrel G, Cheetham T: Juvenile thyrotoxicosis; can we do better? Arch Dis Child 2004; 89:745-750.

52 Zimmerman D: Fetal and neonatal hyperthyroidism. Thyroid 1999;9:727-733.

53 Duprez L, Parma J, Van Sande J, Allgeier A, Leclere J, Schvartz C, Delisle MJ, Decoulx M, Orgiazzi J, Dumont J, et al: Germline mutations in the thyrotropin receptor gene cause non-autoimmune autosomal dominant hyperthyroidism. Nat Genet 1994;7:396-401.

54 Holzapfel HP, Wonerow P, von Petrykowski W, Henschen M, Scherbaum WA, Paschke R: Sporadic congenital hyperthyroidism due to a spontaneous germline mutation in the thyrotropin receptor gene. J Clin Endocrinol Metab 1997;82:3879-3884.

55 Lobo G, Ladron de Guevara D, Zarnello F, Perez A, Vivanco X, Bruggendieck B, Bustos ME, Jimenez C, Donoso C, Brantes J, Becerra C: $\mathrm{Tc}^{99 \mathrm{~m}}$-pertechnetate thyroid scintigraphy in newborns with congenital hypothyroidism. Rev Med Chil 2003;131:283-289. 